\title{
Effects of Excessive Zr Content and Ultrasonic Treatment on Microstructure and Mechanical Properties of Al-Zn-Mg-Cu Alloy
}

\author{
Cheng Li, Shusen Wu*D, Shulin Lü, Jianyu Li, Longfei Liu and Lanqing Xia
}

check for updates

Citation: Li, C.; Wu, S.; Lü, S.; Li, J.; Liu, L.; Xia, L. Effects of Excessive Zr Content and Ultrasonic Treatment on Microstructure and Mechanical Properties of Al-Zn-Mg-Cu Alloy. Metals 2021, 11, 632. https:// doi.org/10.3390/met11040632

Academic Editor: Jonghun Yoon

Received: 1 March 2021

Accepted: 12 April 2021

Published: 13 April 2021

Publisher's Note: MDPI stays neutral with regard to jurisdictional claims in published maps and institutional affiliations.

Copyright: (c) 2021 by the authors. Licensee MDPI, Basel, Switzerland. This article is an open access article distributed under the terms and conditions of the Creative Commons Attribution (CC BY) license (https:// creativecommons.org/licenses/by/ $4.0 /)$.
State Key Lab of Material's Processing and Die \& Mould Technology, School of Materials Science and Engineering, Huazhong University of Science and Technology, Wuhan 430074, China; chauncey_lee@hust.edu.cn (C.L.); shulin317@hust.edu.cn (S.L.); jianyu@hust.edu.cn (J.L.); 1liu329@wisc.edu (L.L.); M201870917@hust.edu.cn (L.X.) * Correspondence: ssw636@hust.edu.cn

\begin{abstract}
The Zr element is one of the important grain refiners for 7xxx series Al-Zn-Mg-Cu alloys, but the effect of $\mathrm{Zr}$ content more than $0.15 \mathrm{wt}$ \% needs to be deeply investigated under the action of ultrasonic vibration. In this study, the effects of $\mathrm{Zr}$ contents ( 0.1 to $0.25 \mathrm{wt} . \%)$ on microstructure and mechanical properties of Al-Zn-Mg-Cu alloy were studied. The results showed that $\mathrm{Zr}$ element could refine grains, but when the $\mathrm{Zr}$ content was greater than $0.15 \mathrm{wt}$.\%, the grain size was not uniform, the number of second phase particles increased, and the segregation of components became more serious. It was found that after ultrasonic treatment, the grain-size inhomogeneity was greatly improved, and the $\mathrm{Zr}$ content could be added up to $0.2 \mathrm{wt}$.\%. When the $\mathrm{Zr}$ content is equal or lower than $0.2 \mathrm{wt} . \%$, ultrasonic treatment can effectively improve the mechanical properties of materials by refining grains and weakening segregation. However, when the $\mathrm{Zr}$ content is up to $0.25 \mathrm{wt} . \%$, the effect is getting worse.
\end{abstract}

Keywords: Al-Zn-Mg-Cu alloy; zirconium; ultrasonic treatment; squeeze casting; composition segregation

\section{Introduction}

Al-Zn-Mg-Cu series alloys have been widely used in aerospace field due to their advantages of light weight, high specific strength, and low cost [1,2]. Nowadays, the realization of vehicle lightweight in the automotive field has become the focus of the entire automotive industry, using Al- $\mathrm{Zn}-\mathrm{Mg}-\mathrm{Cu}$ alloy instead of steel in automotive structural parts $[3,4]$. However, $\mathrm{Al}-\mathrm{Zn}-\mathrm{Mg}-\mathrm{Cu}$ alloy has the characteristics of high alloying degree and wide solidification temperature range, which lead to the defects of ingot, such as shrinkage hole, porosity, and hot cracking. Therefore, ingots generally need plastic processing to reduce the defects. The $\mathrm{Al}-\mathrm{Zn}-\mathrm{Mg}-\mathrm{Cu}$ alloy is mainly rolled into plates for use at present, which is difficult to process into complex parts, greatly restricting the application range of Al-Zn-Mg-Cu alloy.

Squeeze casting is a process to make the melt solidify under high pressure and produce a small amount of plastic deformation, which can effectively reduce the shrinkage cavity and porosity in the casting process, increase the density of the casting significantly, and thus improve the mechanical properties of the casting. Squeeze casting can be directly used to make products with complex shapes and is considered to be the preferred method to achieve the substitution of casting for forging. Hou et al. [5] found that even if the 7A04 aluminum alloy melt was not treated, it could still get better castings after squeeze casting. He et al. [6] showed that the properties of Al-7.2Zn-2.2Mg-1.8Cu-Sc-Zr alloy prepared by squeeze casting were close to those of forgings after heat treatment. However, $\mathrm{Xu}$ [7] found that although squeeze casting can effectively improve the shrinkage cavity and porosity caused by solidification shrinkage, it cannot eliminate the thermal cracking and segregation defects caused by the high alloying characteristics of Al-Zn-Mg-Cu series alloys. 
Trace elements can improve the mechanical properties of aluminum alloy. The influence of trace elements on aluminum alloy is mainly reflected in the refinement of ingot structure, the promotion or inhibition of precipitation phase, and the promotion of new phase precipitation. The commonly used trace elements include $\mathrm{Zr}, \mathrm{Sc}, \mathrm{Li}, \mathrm{Cr}, \mathrm{Ag}$, etc. Among them, addition of Sc or Li to the alloy has a good strengthening effect and is a research hotspot [8-10]. It is found that $\mathrm{Sc}$ elements form $\mathrm{Al}_{3}(\mathrm{Sc}, \mathrm{Zr})$ particles with $\mathrm{Al}$ and $\mathrm{Zr}$ elements during the homogenization process, which significantly improves the properties of aluminum based alloy [11]. However, Sc element is too expensive, which limits their large-scale industrial application. The $\mathrm{Zr}$ element is relatively much cheaper, which can replace expensive elements for microalloying to some extent. However, $\mathrm{Zr}$ only has a significant positive effect when it exists in the form of uniformly distributed fine intermetallic particles in a homogeneous solid solution. It is known that the solubility of zirconium in solid aluminum is low. In conventional casting, the addition of $\mathrm{Zr}$ more than $0.15 \mathrm{wt} . \%$ will result in the appearance of coarse primary phases in the ingot [12]. Chen et al. [13] found that the strength of 7085 alloy increased first and then decreased with the increase of $\mathrm{Zr}$ content. When the optimum $\mathrm{Zr}$ mass fraction was $0.12 \sim 0.14 \mathrm{wt} . \%$, the alloy could maintain high strength and corrosion resistance. Wang et al. [14] found that when $\mathrm{Zr}$ content was $0.157 \mathrm{wt} . \%$, the coarse primary $\mathrm{Al}_{3} \mathrm{Zr}$ phase would appear, which would have adverse effects on the properties of the alloy. When $\mathrm{Zr}$ content was 0.196 $w t . \%$, the aggregation phenomenon of $Z r$ elements was more obvious, and coarser primary $\mathrm{Al}_{3} \mathrm{Zr}$ phase was formed, resulting in a sharp decline in mechanical properties. Therefore, mechanical properties of 7000 series alloys can be promoted to the maximum extent if the addition of $\mathrm{Zr}$ content is as high as possible and $\mathrm{Zr}$ is evenly distributed in the aluminum matrix in the form of fine intermetallic particles, avoiding the formation of coarse primary $\mathrm{Al}_{3} \mathrm{Zr}$ phase.

It is known that cavitation effect and acoustic-streaming effect caused by ultrasonic treatment can homogenize the temperature field and concentration field in the melt, so that a large number of solidification nuclei can be formed simultaneously in the crystallization process, which can refine the microstructure and inhibit elements segregation [15-17]. In this paper, the effects of $\mathrm{Zr}$ content (0.1-0.25 wt.\%) on the microstructure and mechanical properties of Al-Zn-Mg-Cu alloy samples prepared by squeeze casting process (SC) were studied (Section 3.1). Then, Al-Zn-Mg-Cu alloy samples were prepared by ultrasonic treatment and squeeze casting process (UT-SC) to study the effect of ultrasonic treatment on improving the microstructure and properties of the alloy (Section 3.2). The feasibility of using ultrasonic treatment to increase the amount of $\mathrm{Zr}$ element and the mechanism of ultrasonic treatment to improve compositional segregation were investigated (Section 4).

\section{Experimental Procedures}

The compositions of the Al-Zn-Mg-Cu alloys made in this study are shown in Table 1. The main compositions of the four alloys remained the same except that the content of element $\mathrm{Zr}$ was different. The alloy was melted in a resistance furnace and refined by argon degassing at $740{ }^{\circ} \mathrm{C}$ (The melting temperature was determined according to the phase diagram of Al-Zn-Mg-Cu-Zr [18].) for $15 \mathrm{~min}$ and left to rest for $15 \mathrm{~min}$. Al-Zn-Mg-Cu-Zr alloy casting was prepared by ordinary squeeze casting (SC) and squeeze casting after ultrasonic treatment (UT-SC). The casting size was with a diameter of $30 \mathrm{~mm}$ and length in $110 \mathrm{~mm}$. The technique parameters for UT-SC are as follows: Ultrasonic power of $2 \mathrm{kw}$, pouring temperature of $670 \pm 10^{\circ} \mathrm{C}$, squeeze pressure of $100 \mathrm{MPa}$, ultrasonic treatment time of $2 \mathrm{~min}$, preheating temperature of casting mold of $20{ }^{\circ} \mathrm{C}$. In addition to ultrasonic treatment, the same process parameters were used in the ordinary squeeze casting process. For specific ultrasonic and squeeze processes, please see the literature of [19].

The samples for microstructural observation were taken from the middle position of the ingots, and then polished and etched by $0.5 \%$ HF. The microstructure was observed by optical microscope (OM) using a DMM-490C (CAIKON, Shanghai, China), scanning electron microscope (SEM) using a JEOL-7600F (JEOL, Tokyo, Japan), electron probe micro- 
analysis (EMPA) using a EPMA-8050G (SHIMADZU, Tokyo, Japan), and X-ray diffraction (Philips $X^{\prime}$ pert, Almelo, The Netherlands) with a copper target at a scanning speed of $10^{\circ} / \mathrm{min}$ from $20^{\circ}$ to $80^{\circ}$. The tensile mechanical properties were tested by AG-IC100KN universal material testing machine (SHIMADZU, Tokyo, Japan), with the clamping speed of $1.0 \mathrm{~mm} / \mathrm{min}$, and the sample size is shown in Figure 1.

Table 1. Chemical compositions of alloys (wt.\%).

\begin{tabular}{cccccc}
\hline Alloys & Zn & Mg & Cu & Zr & Al \\
\hline A & 6.41 & 1.96 & 2.11 & 0.103 & Bal. \\
B & 6.45 & 1.94 & 2.05 & 0.152 & Bal. \\
C & 6.43 & 1.92 & 2.07 & 0.202 & Bal. \\
D & 6.48 & 1.95 & 2.09 & 0.256 & Bal. \\
\hline
\end{tabular}

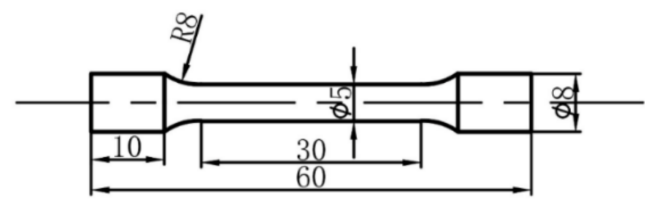

Figure 1. The diagram of tensile sample.

\section{Results}

\subsection{Effect of Excessive Zr Content on Solidification Microstructure}

Figure 2 shows the OM images of as-cast alloys with different $\mathrm{Zr}$ content. Based on grain size statistics (Figure 3), it is found that with the increase of $\mathrm{Zr}$ content, grain size decrease gradually, and alloy B (Figure 2c) has the best grain refinement effect, the average grain size is $56 \mu \mathrm{m}$. However, with the continuous increase of $\mathrm{Zr}$ content, part of the grains become coarse, and the grain inhomogeneity of alloy D (Figure $2 \mathrm{~g}$ ) is particularly serious, minimum grain size is less than $30 \mu \mathrm{m}$, and maximum grain size is more than $120 \mu \mathrm{m}$. At high magnification (Figure $2 \mathrm{~b}, \mathrm{~d}, \mathrm{f}, \mathrm{h}$ ), some black substances with the shape of dots were observed in the crystals, and the amount of black spots increased with the increase of $\mathrm{Zr}$ content. XRD patterns are shown in Figure 4. It can be clearly seen that all of these four alloys consist of $\alpha-\mathrm{Al}$ and $\mathrm{MgZn}_{2}$ phases. The different $\mathrm{Zr}$ contents did not change the main phases of the alloys.
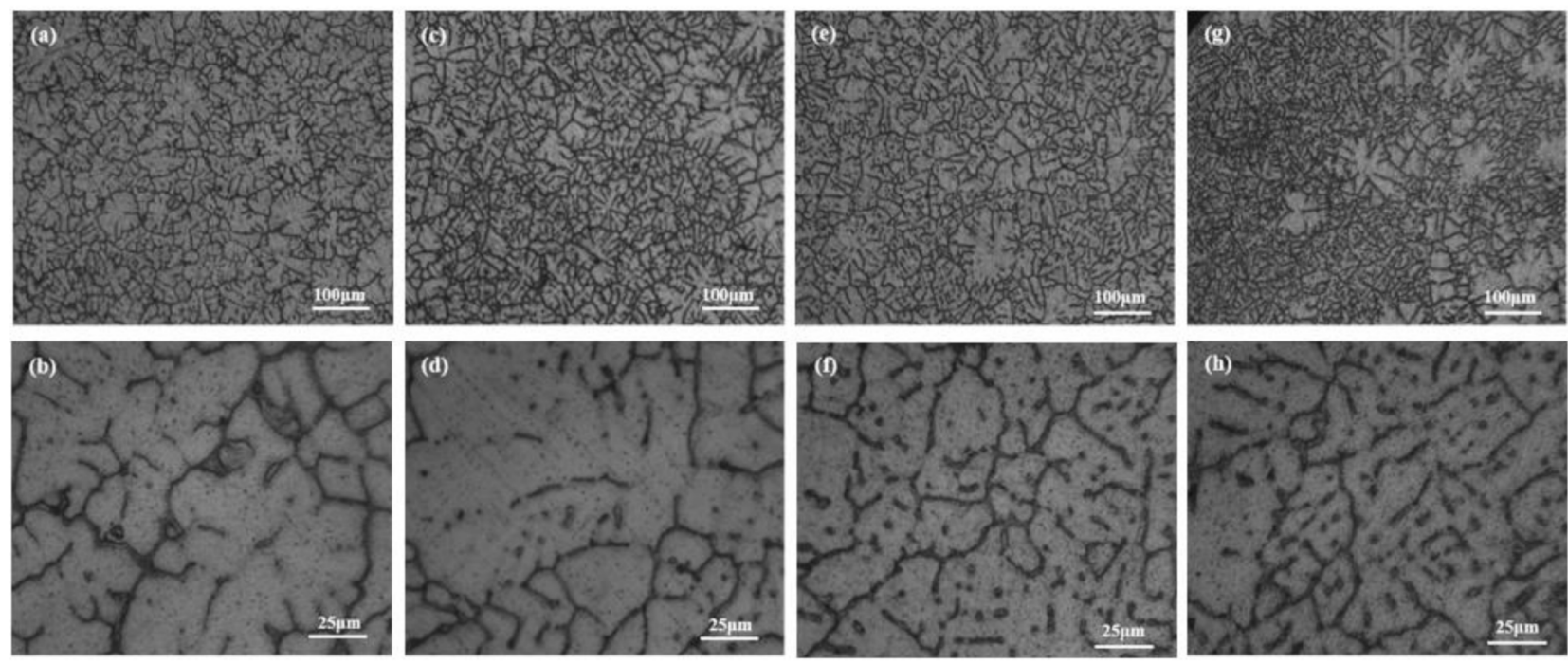

Figure 2. OM (optical microscope) images of alloys with different $\mathrm{Zr}$ content: (a,b) Alloy A: 0.10\%; (c,d) alloy B: 0.15\%; (e,f) alloy C: $0.20 \%$; (g,h) alloy D: $0.25 \%$. 


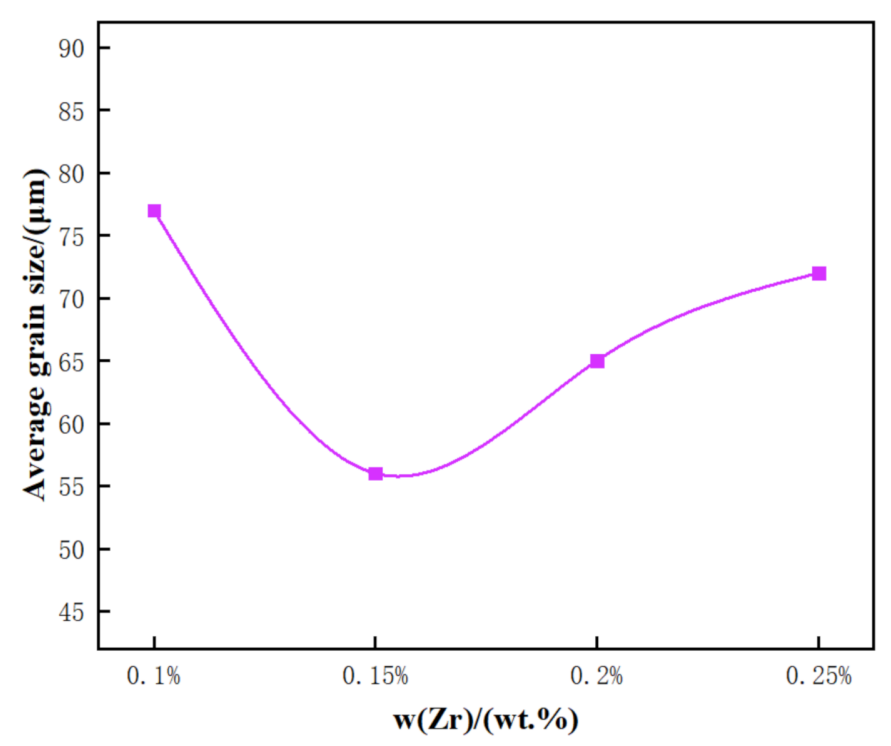

Figure 3. The variation of average grain size with $\mathrm{Zr}$ content.

Figure 4 shows the typical eutectic phase of as-cast $\mathrm{Al}-\mathrm{Zn}-\mathrm{Mg}-\mathrm{Cu}$ alloy by SEM. The dark areas are the primary solid solution $\alpha-\mathrm{Al}$, and the bright areas are the nonequilibrium eutectic phases. The Energy Dispersive Spectroscopy (EDS) analysis results are listed in Table 2. It can be seen from Figure $5 \mathrm{a}, \mathrm{b}$ that there are a large number of non-equilibrium eutectic phases in the as-cast structure of the alloy, which are distributed in the grain boundary in the form of network, and there are many second phases in the grain. According to EDS analysis results, the second phase in the grain is the quaternary phase of $\mathrm{Al} \mathrm{ZnMgCu}$ (Points $\mathrm{A}, \mathrm{B}$ ), and the content of $\mathrm{Zn}, \mathrm{Mg}$, and $\mathrm{Cu}$ is relatively high. The non-equilibrium eutectic phase at grain boundary is mainly composed of $\alpha(\mathrm{Al})$ and an $\mathrm{AlZnMgCu}$ quaternary phase (Points $\mathrm{C}, \mathrm{D}$, and $\mathrm{F}$ ), and a small amount of $\mathrm{Al}_{2} \mathrm{Cu}$ phase (Point $\mathrm{E}$ ) is also found. AlCuFe phase (Point $\mathrm{G}$ ) is also found at some grain boundaries. The composition of the non-equilibrium eutectic phases did not change much in each sample alloy.

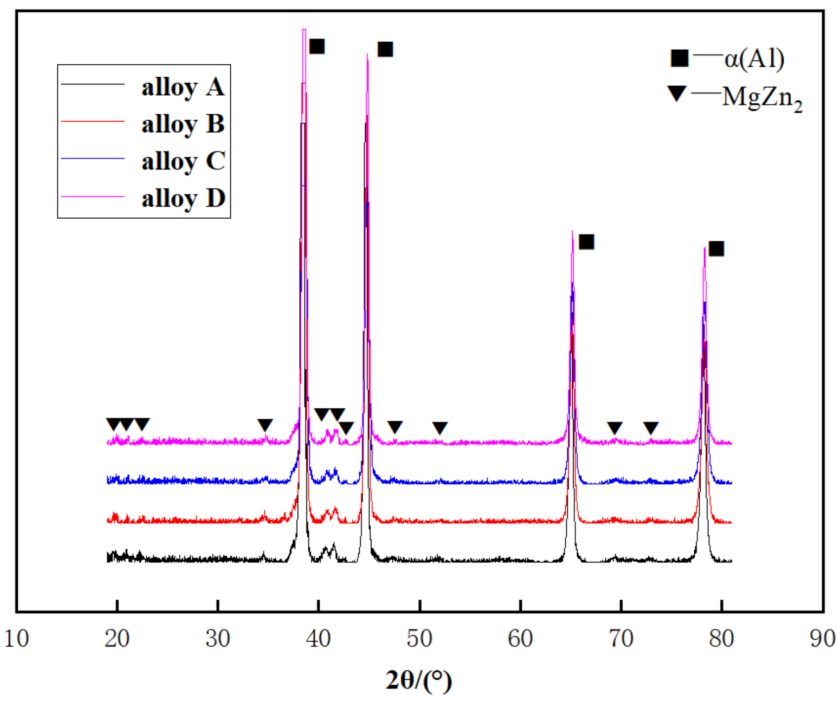

Figure 4. XRD patterns of alloys with different $\mathrm{Zr}$ content. 

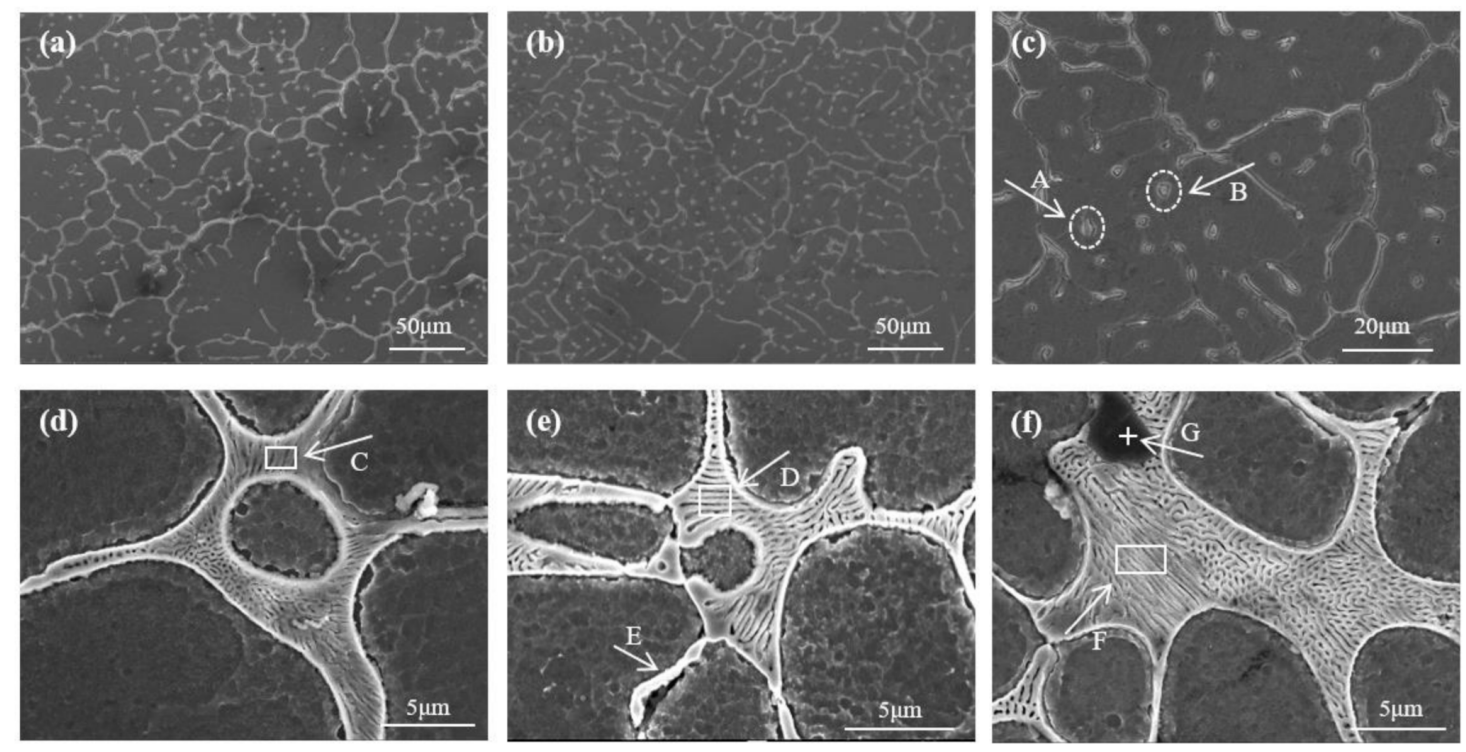

Figure 5. SEM (scanning electron microscope) images of squeeze casting process (SC) sample alloy with different magnifications (wt.\%): (a,d) Alloy A; (e) alloy C; (b,c,f) alloy D.

Table 2. EDS analysis of constituent phases in Figure 3 (at.\%).

\begin{tabular}{cccccc}
\hline Phases & Al & Zn & Mg & Cu & Fe \\
\hline A & 25.53 & 24.42 & 30.10 & 19.95 & 0 \\
B & 28.29 & 22.37 & 29.45 & 19.89 & 0 \\
C & 66.27 & 12.32 & 10.63 & 10.78 & 0 \\
D & 58.00 & 14.27 & 11.97 & 15.76 & 0 \\
E & 67.58 & 0 & 1.01 & 31.41 & 0 \\
F & 55.70 & 13.03 & 13.36 & 17.91 & 0 \\
G & 73.35 & 0 & 0 & 16.39 & 10.25 \\
\hline
\end{tabular}

Since the content of $\mathrm{Zr}$ element is much lower than other main alloying elements, it is difficult to observe the segregation of $\mathrm{Zr}$ in as-cast condition. Therefore, alloy $\mathrm{C}$ after solution heat treatment was detected by electron microprobe. Figure 6 shows Backscattered Electron (BSE) images of SC sample (alloy C) after solid solution treatment and its Electron Probe Microanalysis (EPMA) elemental map for Zr. The bright color indicates that the concentration of $\mathrm{Zr}$ is higher in this area. It is found that there are many insoluble phases containing $\mathrm{Zr}$ from Figure $6 \mathrm{~b}$. Due to the low diffusion coefficient of $\mathrm{Zr}$ element, it is difficult to form a new large-size phase during heat treatment. Therefore, these Zr-containing insoluble phase are formed due to the aggregation of $\mathrm{Zr}$ during solidification. The $\mathrm{Zr}$ containing phase is distributed in a strip or a disc shape (Figure 6c). The EDS analysis result of point $A$ is shown in Figure $6 \mathrm{~d}$. The elements at the center of the strip-like second phase are $\mathrm{Al}$ and $\mathrm{Zr}$, and the atomic ratio is about 3:1, which can be inferred to be primary $\mathrm{Al}_{3} \mathrm{Zr}$ phase. It also proves that when $\mathrm{Zr}$ content is high, $\mathrm{Zr}$ elements tend to aggregate to form primary $\mathrm{Al}_{3} \mathrm{Zr}$ phase. The phase has high thermal stability, which is difficult to be eliminated by conventional heat treatment and will inevitably affect the properties of the material.

\subsection{Effect of Ultrasonic Treatment on Microstructure and Mechanical Properties}

Figure 7 shows the SEM images of each sample treated by ultrasound of the melts. It can be found that after the ultrasonic treatment, the grain size is refined and uniform, and the grain shape is mostly equiaxed crystal. It was found that the average grain size decreased from $50 \mu \mathrm{m}$ to $30 \mu \mathrm{m}$ with the inscrease of $\mathrm{Zr}$ content from $0.1 \%$ to $0.25 \%$. In addition, the second phase disappeared completely after the ultrasonic treatment. However, 
for alloy $\mathrm{D}$, it was found that some of the regional grains were too small, leading to the formation of large-sized grain boundary eutectic phases around them (Figure $7 \mathrm{~h}$ ). The coarse eutectic phase around grain boundary will affect the heat treatment in the later period, which will lead to the deterioration of the mechanical properties of the sample.

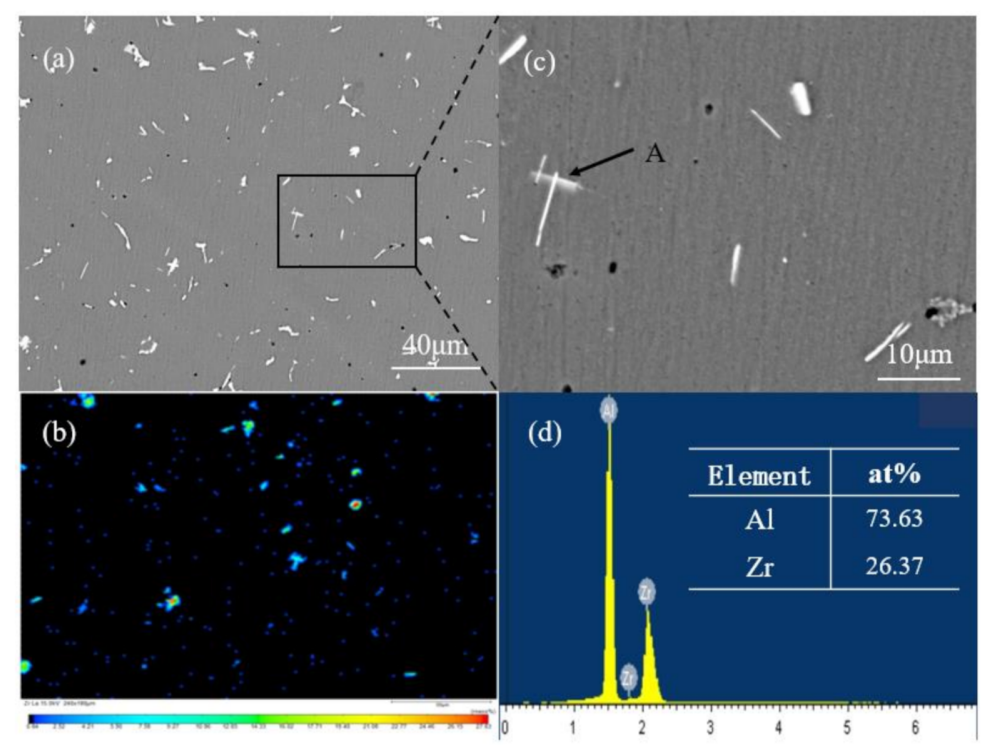

Figure 6. $(\mathbf{a}, \mathbf{c})$ The BSE images of alloy $\mathrm{C}$ after solution treatment; (b) The EPMA elemental map for $\mathrm{Zr}$ of alloy $\mathrm{C}$ after solution treatment; (d)The EDS analysis result of point A.
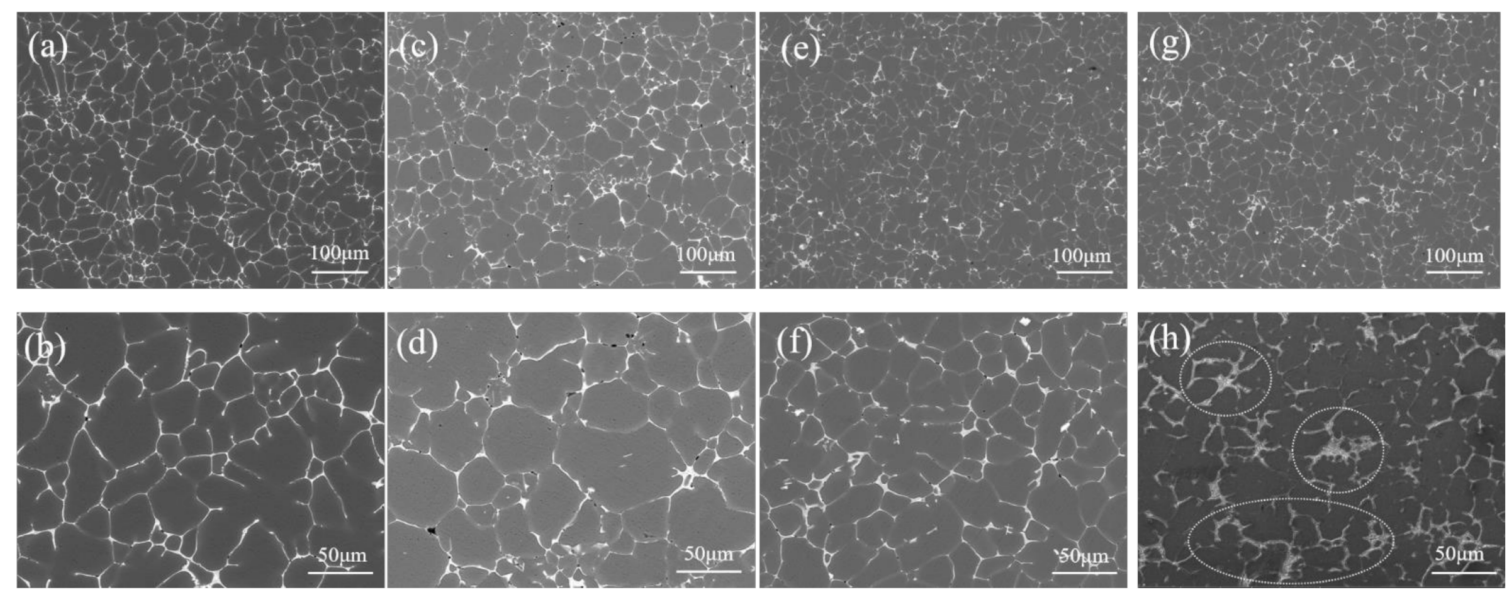

Figure 7. SEM images of ultrasonic treatment and squeeze casting process (UT-SC) alloys with different Zr content: (a,b) Alloy A; (c,d) alloy B; (e,f) alloy C; (g,h) alloy D.

Figure 8 shows the BSE images of UT-SC samples. The EDS analysis results of points are listed in Table 3. The non-equilibrium eutectic phase was still mainly composed of $\mathrm{T}(\mathrm{AlZnMgCu})$ phase (points $\mathrm{A}$ and $\mathrm{D})$, so the melt ultrasonic treatment did not affect the compositions of eutectic phase. The morphology of non-equilibrium eutectic phase is mainly point-like and partly lamellar. Some AlCuFe phases (points B and C) were still found in the samples, which also indicated that the ultrasonic treatment could not completely eliminate the iron-rich phase.

Figure 9 shows the XRD results of SC sample and UT-SC sample $\left(20^{\circ}-80^{\circ}\right)$. It is found that the main phases of both samples are $\alpha-\mathrm{Al}$ matrix phase and $\mathrm{MgZn}_{2}$ phase, indicating that the ultrasonic treatment does not change the main phases compositions of the alloy. In addition, compared with the SC sample, $\alpha$-Al peak of UT-SC sample shifted to the left 
(diffraction Angle decreased), while other diffraction peaks remained basically unchanged. This phenomenon may be caused by the increase of solubility of alloy elements in $\alpha$-Al due to ultrasonic treatment.

Table 3. EDS analysis of constituent phases in Figure 6 (at.\%).

\begin{tabular}{cccccc}
\hline Phases & $\mathbf{A l}$ & $\mathbf{Z n}$ & $\mathbf{M g}$ & $\mathbf{C u}$ & $\mathbf{F e}$ \\
\hline A & 46.13 & 16.41 & 24.92 & 12.54 & 0 \\
B & 70.54 & 1.59 & 1.33 & 13.84 & 12.71 \\
C & 68.12 & 3.98 & 0 & 15.82 & 12.08 \\
D & 42.73 & 26.86 & 12.32 & 18.09 & 0 \\
\hline
\end{tabular}
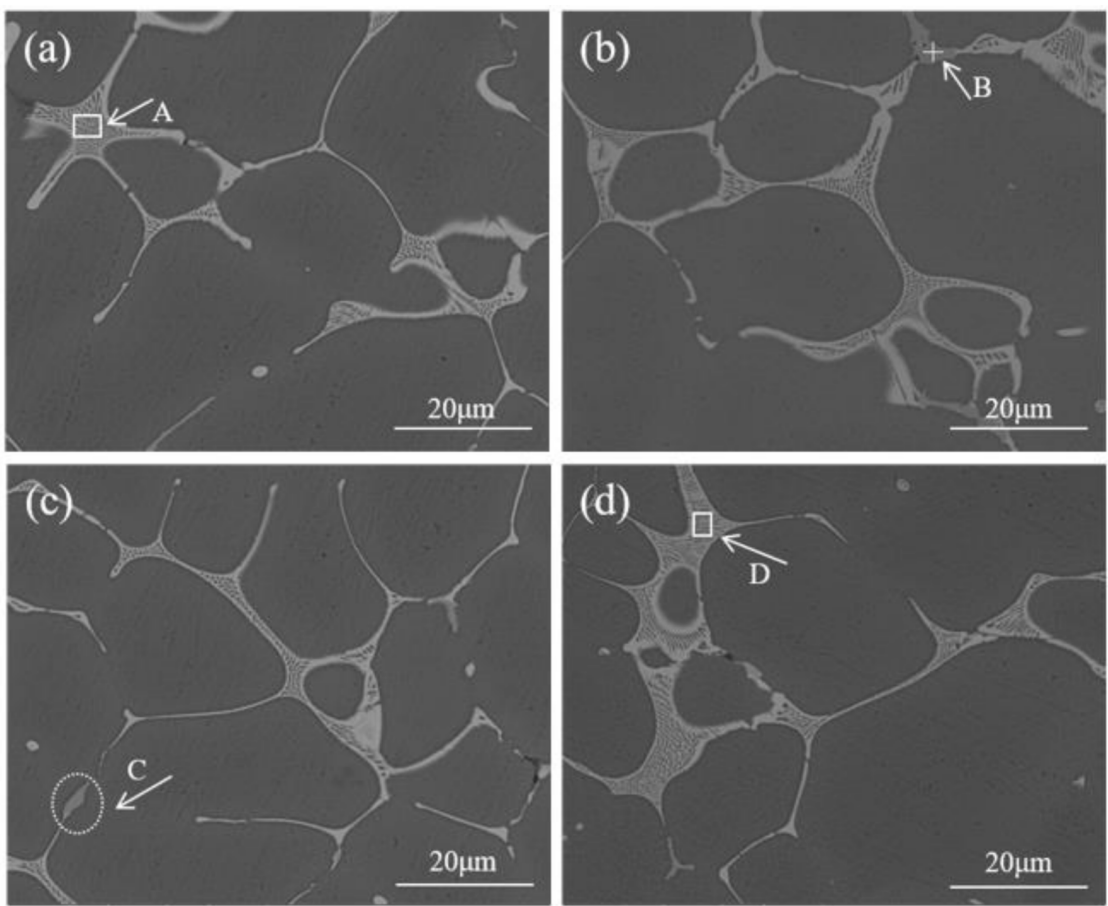

Figure 8. BSE images of UT-SC sample alloy with different Zr content: (a) Alloy A; (b) alloy B; (c) alloy $\mathrm{C}$; (d) alloy D.

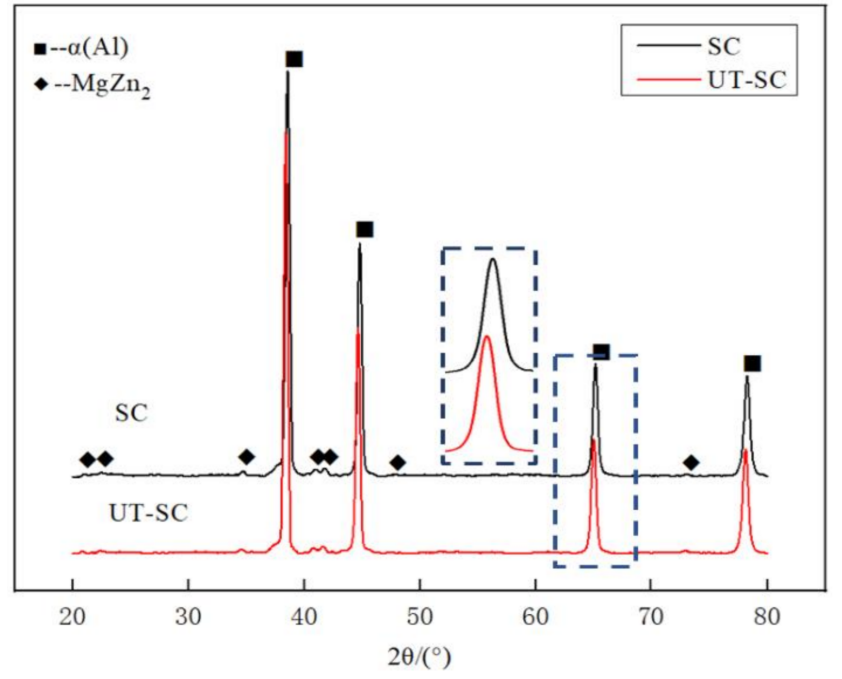

Figure 9. XRD patterns of SC and UT-SC for alloy C. 
Figures 10 and 11 show the electron microprobe elemental maps of SC and UT-SC samples (alloy C), respectively. Compared with SC sample, the secondary phase of UT-SC sample is obviously smaller. The concentration of $\mathrm{Zn}$ and $\mathrm{Mg}$ in grain boundaries in SC sample is higher than UT-SC sample. It can be seen that $\mathrm{Cu}$ only exists in the grain boundaries in both alloys, because the diffusion coefficient of $\mathrm{Cu}$ is smaller than that of $\mathrm{Mg}$ and $\mathrm{Zn}$ at the same temperature. The results of EPMA mapping indicate that there is severe element segregation in SC sample. This is because of the high alloying degree of 7000 series alloys and the low diffusion coefficient of $\mathrm{Zn}, \mathrm{Mg}$, and $\mathrm{Cu}$, which leads to the tendency of alloying elements to gather at grain boundary during solidification. However, this can be largely reduced by ultrasonic treatment.
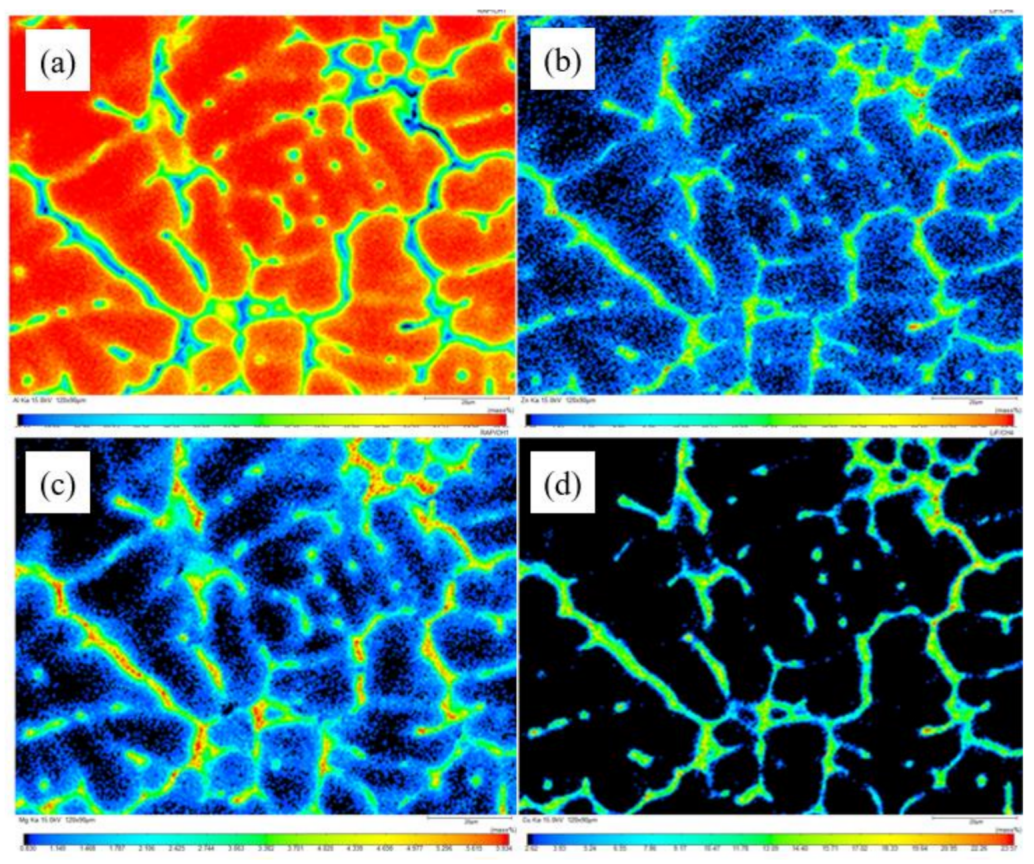

Figure 10. Main elemental distribution in SC sample of Alloy C: (a) $\mathrm{Al}$; (b) $\mathrm{Zn}$; (c) $\mathrm{Mg}$; (d) Cu.
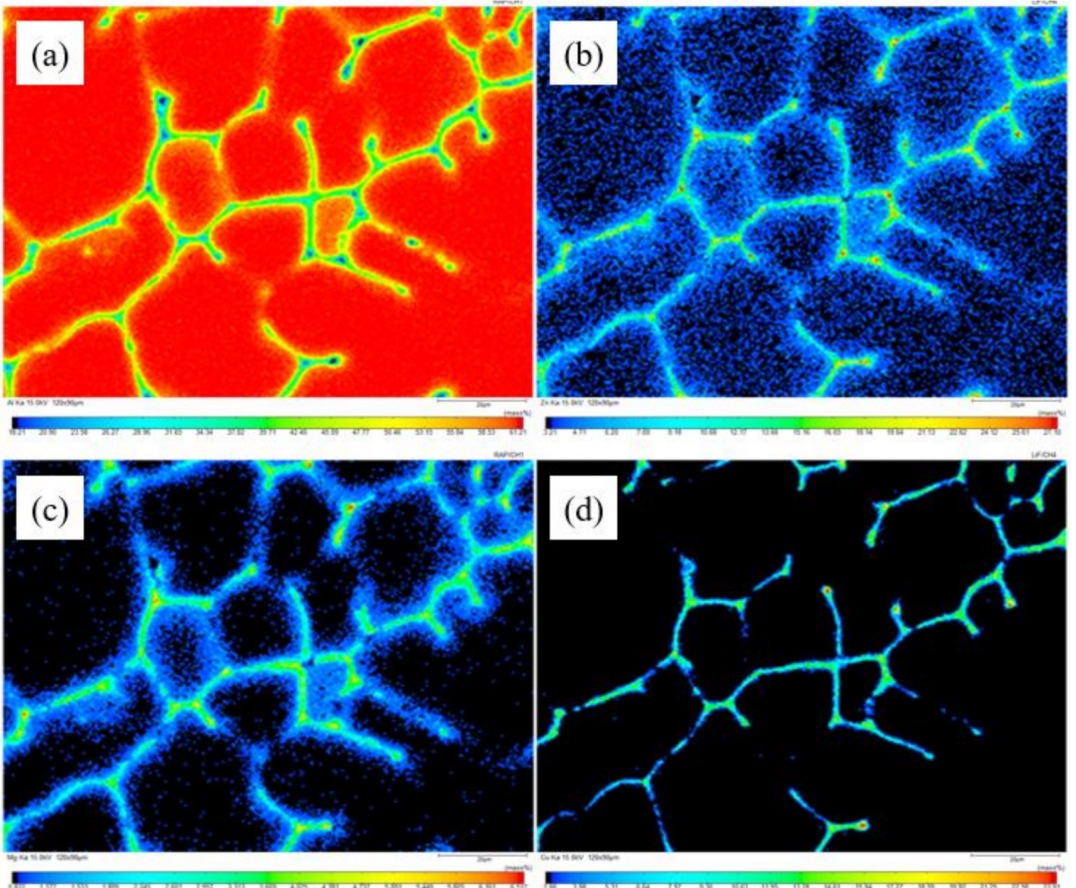

Figure 11. Main elemental distribution in UT-SC sample of alloy C: (a) $\mathrm{Al}$; (b) Zn; (c) $\mathrm{Mg}$; (d) $\mathrm{Cu}$. 
Figure 12 shows the BSE image of UT-SC sample (alloy C) after solid solution treatment and its electron microprobe elemental map. It can be seen that no $\mathrm{Zr}$-containing phase is found, indicating that ultrasonic treatment can play a good role in inhibiting the accumulation of $\mathrm{Zr}$ elements. The residual insoluble phase contains mainly $\mathrm{Cu}$ and $\mathrm{Fe}$ elements, which also proves that the Fe-rich phase cannot be eliminated by ultrasonic treatment, but can be refined.

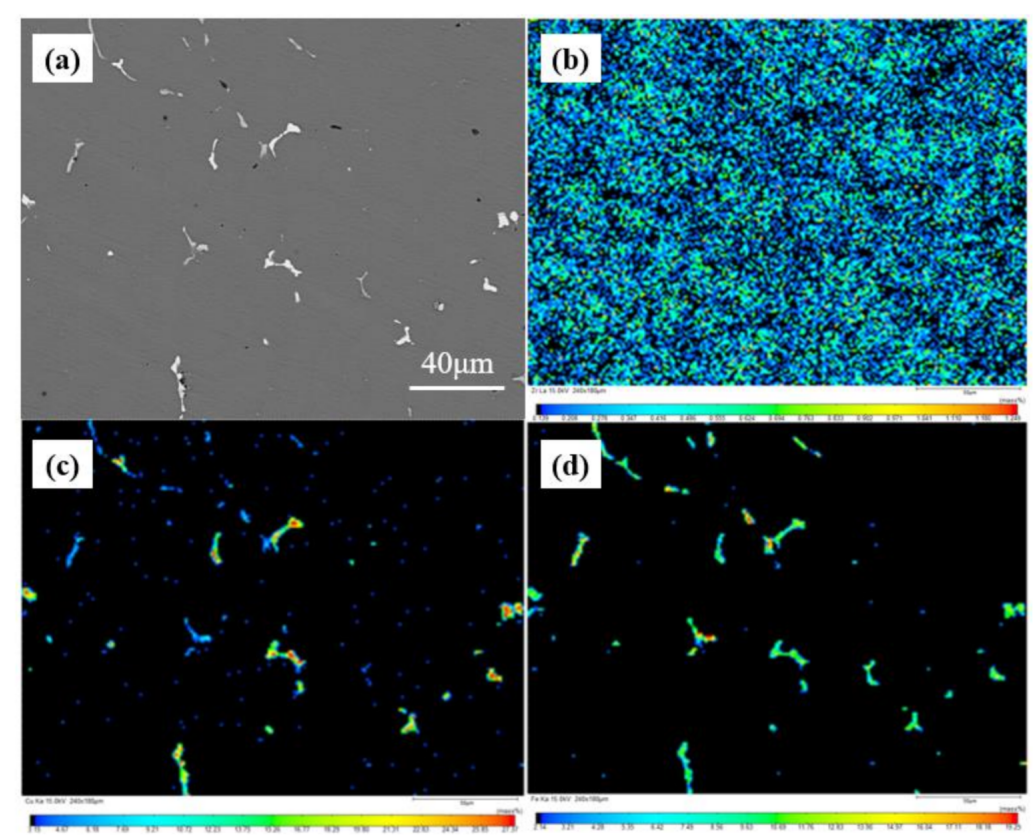

Figure 12. BSE of UT-SC sample of alloy $C$ after solution treatment (a) and its electron microprobe elemental map (b) $\mathrm{Zr}$; (c) $\mathrm{Cu}$; (d) Fe.

Figure 13 shows the tensile strength and elongation of SC and UT-SC samples in as-cast state with different $\mathrm{Zr}$ content. For SC samples, when the $\mathrm{Zr}$ content is lower than $0.15 \%$, the tensile strength increases from $335 \mathrm{MPa}$ to $354 \mathrm{MPa}$ with the increase of $\mathrm{Zr}$ content. This is due to the grain refinement effect of $\mathrm{Zr}$ element, which increases the number of grains per unit volume. In the case of stress deformation, the deformation is dispersed to more grains, thus enhancing the tensile strength. When the content of $\mathrm{Zr}$ continues to increase to $0.25 \%$, the tensile strength decreases significantly, from $354 \mathrm{MPa}$ to $323 \mathrm{MPa}$. This is because the grain size is not uniform (as shown in Figure 2g) and local stress concentration occurs during the stretching process, leading to the decrease of tensile strength. Ultrasonic treatment can further refine grain size and uniform size, so the tensile strength of UT-SC sample is obviously higher than that of SC sample. When $\mathrm{w}(\mathrm{Zr})=0.20 \mathrm{wt} . \%$, the tensile strength reaches the maximum (379 MPa). The elongation of the SC sample decreased from $5.2 \%$ to $3.6 \%$ with the increase of $\mathrm{Zr}$ content, which was due to the decrease of plasticity caused by the increase of the brittle second phase (as shown in Figure 5c) in the grain. Ultrasonic treatment can well weaken segregation and eliminate the second phases in the grain, so the elongation of UT-SC sample is much higher than that of SC sample, and when $\mathrm{w}(\mathrm{Zr})=0.20 \mathrm{wt} . \%$, the elongation reaches the maximum $(7.5 \%)$. Although the grain size of the sample $(\mathrm{w}(\mathrm{Zr})=0.25 \mathrm{wt} . \%)$ was refined and uniform after ultrasonic treatment, the local intergranular non-equilibrium eutectic phase was large (as shown in Figure 7h), resulting in reduced tensile strength and elongation. 

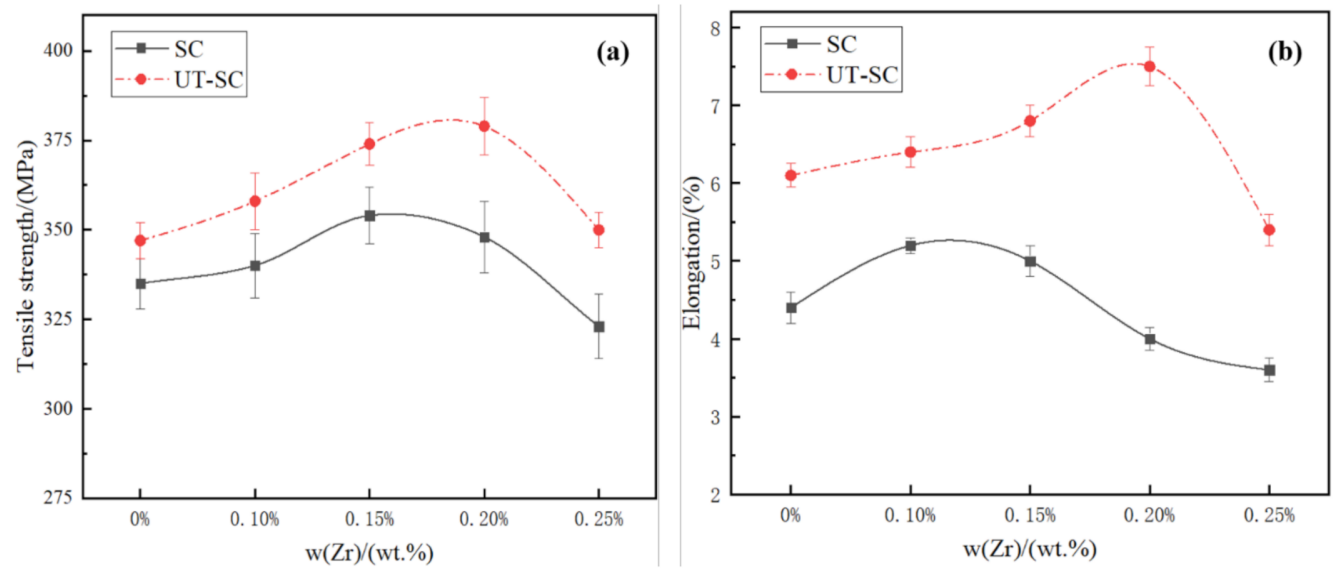

Figure 13. Tensile strength (a) and elongation(b) in as-cast state of SC and UT-SC samples with different Zr.

\section{Discussion}

Through the above experimental results, it can be found that with the increase of $\mathrm{Zr}$ content, the segregation of compositions becomes more serious, and many second phases appear in the crystal grains. The serious compositions segregation is due to the accumulation of $\mathrm{Zr}$ element at the front of the solidification interface, which leads to increased constitutional overcooling [20]. The existence of constitutional undercooling is not only an important driving force for crystal growth, but also the main impetus for crystal nucleation. The area where the $\mathrm{Zr}$ element is concentrated due to the high degree of undercooling has a higher nucleation rate and a faster crystallization rate than other areas of the melt, and the alloying elements cannot be diffused uniformly. The result is that the chemical compositions of each crystal grain is very uneven. At the early crystallization site, the grains are small and the amount of second phases in the crystal is big. At the later crystallization site, the grains are relatively large and the amount of second phases in the crystal is small. At the same time, there is also a difference in elements concentration inside the grains, which leads to intragranular segregation. Severe intragranular segregation will reduce the mechanical properties of the alloy, especially the plasticity and toughness, and will also reduce the corrosion resistance of the alloy.

The acoustic cavitation effect and streaming effect caused by ultrasound in the melt will cause macro turbulence in the melt, breaking the solid rigid framework of the crystals, forming a large number of dispersed liquid transmission channels, and forming a microporous medium [21]. The enriched solutes at the front of the solid-liquid interface are rapidly diffused, the segregation of $\mathrm{Zr}$ elements is inhibited, and the composition distribution is more uniform. When ultrasound is applied, a sound flow is formed on the lower end of the amplitude rod, and an overall circulation is caused in the entire melt, forming a large-scale stirring effect on the melt. This stirring changes the distribution of the melt flow field and balances temperature field and concentration field. This will increase the overall undercooling of the melt and accelerate the cooling rate of the solidification front [22]. In this way, a large number of nucleation cores in the entire liquid during crystallization process can be made simultaneously. Under the combined effect of ultrasonic cavitation effect and streaming effect, the grain size is reduced, the microstructure is refined, the second phase in the crystal is minimized, and the segregation phenomenon is improved.

In the ultrasonic field, the solidification model of solute non-diffusion in solid phase and mixed diffusion in liquid phase is adopted to describe the redistribution behavior of solute elements. The solute distribution is as follows [23]:

$$
\mathrm{C}_{\mathrm{S}}(x)=\mathrm{C}_{0}\left[1-(1-k) \exp \left(-k \frac{R}{D_{L}} x\right)\right]
$$

where $\mathrm{C}_{\mathrm{s}}(x)$ is the mass fraction of solute at $x ; x$ is the distance between the point in the liquid phase and the front edge of the solid-liquid interface; $R$ is the solidification 
rate; $D_{L}$ is the diffusion coefficient; $k$ is effective distribution coefficient. $C_{0}$ is the solute mass fraction in the liquid phase. It can be seen from Equation (1) that the solidification rate is a key factor affecting the solute distribution. Ultrasonic treatment can obviously accelerate the overall solidification process of the melt, this will reduce the retention period of solute elements in solid phase and liquid phase, more $\mathrm{Zn}, \mathrm{Mg}$, and $\mathrm{Cu}$ dissolve into the $\alpha-\mathrm{Al}$ matrix, which reduces the content of $\mathrm{Zn}, \mathrm{Mg}$, and $\mathrm{Cu}$ in the liquid phase at the later stage of solidification. Ultrasound increases the solute mass fraction $\mathrm{C}_{\mathrm{S}}$ in the solid phase and decreases the solute mass fraction $C_{\mathrm{L}}$ in the liquid phase. From $k=\mathrm{C}_{\mathrm{S}} / \mathrm{C}_{\mathrm{L}}$, the effective partition coefficient of solute $k$ increases. Figure 14 shows the distribution of solute elements near the solid-liquid interface of alloy solidification under SC and UT-SC conditions. It can be seen that during the solidification of the molten metal, a concentration gradient is formed in the liquid boundary layer of the solidification interface. Ultrasound accelerates the solidification rate, and the alloy elements in the melt do not have enough time to diffuse into the liquid phase at the front of the interface, and are directly dissolved in the $\alpha$-Al matrix, resulting in an increase in the solid solubility of the alloy elements in the crystal. This is beneficial to reduce the degree of segregation and is also beneficial to element diffusion during homogenization and solid solution.

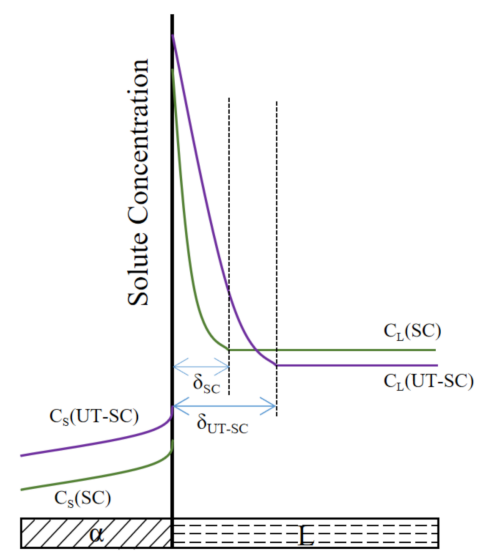

Figure 14. Solute element distribution at solid-liquid interface under SC and UT-SC processes.

The above research results show that the combination of ultrasonic treatment and squeeze casting can produce excellent $\mathrm{Al}-\mathrm{Zn}-\mathrm{Mg}-\mathrm{Cu}$ alloy ingot. Ultrasonic treatment can effectively reduce the composition segregation of $\mathrm{Al}-\mathrm{Zn}-\mathrm{Mg}-\mathrm{Cu}$ alloy, increase contents of alloying elements in solid solution, and facilitate the precipitation of aging strengthening phase, therefore improving the mechanical properties of the final casting to achieve casting instead of forging. In addition, ultrasonic treatment can increase the addition amount of $\mathrm{Zr}$ element to $0.2 \mathrm{wt} . \%$, and more $\mathrm{Al}_{3} \mathrm{Zr}$ particles will be precipitated in the homogenization process, which can inhibit the growth of recrystallized grains in the subsequent deformation process and improve the properties of the alloy. The forming process and method adopted in this paper can be applied to industrial production completely, and provides certain theoretical basis for the possible practical application of this new process in the future.

\section{Conclusions}

The $\mathrm{Zr}$ element has a certain effect of grain refinement, but when its content is higher than $0.15 \mathrm{wt} . \%$, there will be uneven grain refinement. The maximum grain size is more than $120 \mu \mathrm{m}$, while the minimum grain size is less than $30 \mu \mathrm{m}$, and the grain size difference is large at $0.25 \mathrm{wt} . \% \mathrm{Zr}$. In addition, with the increase of $\mathrm{Zr}$ content, the composition segregation was serious, a large number of second phases appeared in the grains, and the $\mathrm{Zr}$ element segregates, forming many primary $\mathrm{Al}_{3} \mathrm{Zr}$ phases.

The cavitation and acoustic streaming effect caused by ultrasonic treatment improves the redistribution ability of solute elements in the solid-liquid interface front, accelerates the cooling speed of solidification front, and increases the solid solution amount of $\mathrm{Zn}$, 
$\mathrm{Mg}$, and $\mathrm{Cu}$ in $\alpha$-Al. The non-equilibrium eutectic phase is small, and the second phase in the grain disappears, weakening segregation effectively. In addition, ultrasonic treatment can inhibit the segregation of $\mathrm{Zr}$ elements and prevent the formation of a large amount of primary $\mathrm{Al}_{3} \mathrm{Zr}$ phase.

Under ultrasonic treatment, the $\mathrm{Zr}$ content can be added up to $0.2 \mathrm{wt} . \% \mathrm{Zr}$, and ultrasonic treatment can effectively improve the mechanical properties of this $\mathrm{Al}-\mathrm{Zn}-\mathrm{Mg}$ $\mathrm{Cu}$ alloy by refining grains and weakening segregation. However, when the $\mathrm{Zr}$ content is as high as $0.25 \mathrm{wt} . \%$, the $\alpha$-Al grains can be refined, but the size of intergranular nonequilibrium eutectic phase is enlarged, resulting in the decline of mechanical properties.

Author Contributions: Conceptualization, S.W.; Formal analysis, S.L., J.L. and L.X.; Methodology, L.L.; Writing - original draft, C.L. All authors have read and agreed to the published version of the manuscript.

Funding: This work was supported by R \& D projects in key areas of Guangdong Province (No. 2019B090921001), and by the project JCKY 2016209A001.

Data Availability Statement: The raw/processed data required to reproduce these findings cannot be shared at this time due to technical or time limitations.

Acknowledgments: The authors would like to express their appreciation to Analytical and Testing Center, HUST.

Conflicts of Interest: The authors declare no conflict of interest.

\title{
Nomenclature
}

\author{
SC Squeeze casting; \\ UT-SC Ultrasonic treatment and squeeze casting; \\ $x \quad$ Distance between the point in the liquid phase and the front edge of the solid-liquid interface; \\ $\mathrm{C}_{\mathrm{S}}(x) \quad$ Mass fraction of solute at $x$; \\ $\mathrm{C}_{0} \quad$ Solute mass fraction in the liquid phase; \\ $R \quad$ Solidification rate; \\ $D_{L} \quad$ Diffusion coefficient; \\ $k \quad$ Effective distribution coefficient;
}

\section{References}

1. Liu, J. Advanced aluminum and hybrid aerostructures for future aircraft. Mater. Sci. Forum 2006, 519-521, 1233-1238. [CrossRef]

2. Dursun, T.; Soutis, C. Recent developments in advanced aircraft aluminum alloys. Mater. Des. 2014, 56, 862-871. [CrossRef]

3. Hirsch, J. Recent development in aluminum for automotive applications. Trans. Nonferrous Met. Soc. China 2014, $24,1995-2002$. [CrossRef]

4. Hirsch, J. Aluminum in Innovative Light-Weight Car Design. Mater. Trans. 2011, 52, 818-824. [CrossRef]

5. Hou, L.Q.; Xing, Z.Y.; Li, S.M. Microstructure and properties of commonly used aluminum alloy in squeeze casting. Spec. Cast. Nonferrous Alloys 2013, 33, 1021-1023.

6. He, M.; Li, B.; Gao, Z.H.; Xu, J. Effect of Sc on microstructure of Al-Zn-Mg-Cu-Zr alloy by squeeze casting. Spec. Cast. Nonferrous Alloys 2016, 36, 597-600.

7. $\mathrm{Xu}, \mathrm{L}$. Research on Rheological Squeeze Casting Technology and Numerical Simulation of 7000 Series Aluminum Alloy. Ph.D. Thesis, Research Institute of Nonferrous Metals, Beijing, China, 2014.

8. Li, Z.M.; Jiang, H.C.; Wang, Y.L.; Zhang, D.; Yan, D.S. Effect of minor Sc addition on microstructure and stress corrosion cracking behavior of medium strength Al-Zn-Mg alloy. J. Mater. Sci. Technol. 2018, 34, 1172-1179. [CrossRef]

9. He, Y.D.; Zhang, X.M.; You, J.H. Effect of minor Sc and Zr on microstructure and mechanical properties of Al-Zn-Mg-Cu alloy. Trans. Nonferrous Met. Soc. China 2006, 16, 1228-1235. [CrossRef]

10. Yin, Z.M.; Pan, Q.L.; Zhang, Y.H.; Jiang, F. Effect of minor Sc and Zr on the microstructure and mechanical properties of Al-Mg based alloys. Mater. Sci. Eng. A 2000, 280, 151-155. [CrossRef]

11. Kishchik, A.A.; Mikhaylovskaya, A.V.; Kotov, A.D.; Portnoy, V.K. Effect of Homogenization Treatment on Superplastic Properties of 360 Aluminum Based Alloy with Minor Zr and Sc Additions. Defect Diffus. Forum 2018, 385, 84-89. [CrossRef]

12. Eskin, G.I.; Makarov, G.S. Effect of ultrasonic processing of molten metal on structure formation and improvement of properties of high-strength Al-Zn-Mg-Cu-Zr alloys. Adv. Perform. Mater. 1995, 2, 43-50. [CrossRef]

13. Chen, S.D.; Jiao, H.B.; Chen, S.Y.; Huang, L.P.; Chen, K.H.; Ma, Y.L. Effects of Zr content on microstructure properties of anisotropy of 7085 aluminum alloy. J. Cent. South Univ. (Sci. Technol.) 2018, 49, 1349-1357. 
14. Wang, Y.L.; Ma, Y.L.; Huang, Y.C.; Zhang, Q.; Tan, W.Y. Effect of Zr Element on Microstructure and Mechanical Properties of Al-Zn-Mg Alloy. Hot Work. Technol. 2019, 48, 40-45.

15. Yao, L.; Hao, H.; Ji, S.H. Effects of ultrasonic vibration on solidification structure and properties of Mg-8Li-3Al alloy. Trans. Nonferrous Met. Soc. China 2011, 21, 1241-1246. [CrossRef]

16. Kotadia, H.R.; Das, A. Modification of solidification microstructure in hypo and hyper-eutectic Al-Si alloys under high-intensity ultrasonic irradiation. J. Alloys Compd. 2015, 620,1-4. [CrossRef]

17. Huang, H.J.; Xu, Y.F.; Shu, D.; Han, Y.F.; Wang, J.; Sun, B.D. Effect of ultrasonic melt treatment on structure refinement of solidified high purity aluminum. Trans. Nonferrous Met. Soc. China 2014, 24, 2414-2419. [CrossRef]

18. Rokhlin, L.L.; Dobatkina, T.V.; Bochvar, N.R. Investigation of phase equilibria in alloys of the Al-Zn-Mg-Cu-Zr-Sc system. J. Alloys Compd 2004, 367, 10-16. [CrossRef]

19. Fang, X.G.; Lü, S.L.; Wang, J.; Yang, X.; Wu, S.S. Microstructure and mechanical properties of a novel Mg-RE-Zn-Y alloy fabricated by rheo-squeeze casting. Mater. Des. 2016, 94, 353-359. [CrossRef]

20. Wang, Y.H.; Zhang, F.M.; Gao, G. Refining Treatment of Deformed Aluminum Alloy; Metallurgical Industry Press: Beijing, China, 1988; p. 43.

21. Chen, D.; Zhang, H.; Wang, X.; Cui, J. Investigation on microsegregation of Al-45\%Cu alloy produced by low frequency electromagnetic casting. Acta Metall. 2011, 47, 185-190.

22. Yasuda, K.; Saiki, Y.; Kubo, T.; Kuwabara, M. Influence of High-Power Ultrasonic Irradiation on Primary Nucleation Process during Solidification. Jpn. J. Appl. Phys. 2014, 46, 4939-4944. [CrossRef]

23. Wu, S.S.; Liu, Y.Q. Principle of Materials Forming; China Machine Press: Beijing, China, 2008; p. 63. 